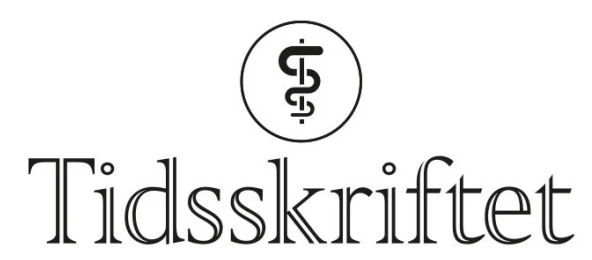

DEN NORSKE LEGEFORENING

\title{
Rehabilitering etter covid-19
}

\author{
KRONIKK
}

\section{FRANK BECKER}

frank.becker@sunnaas.no

Frank Becker er klinikkoverlege ved Sunnaas sykehus og førsteamanuensis i fysikalsk medisin og rehabilitering ved Institutt for klinisk medisin ved Universitetet i Oslo. Han leder Fagråd rehabilitering i Helse $S \emptyset r-\emptyset$ st.

Forfatteren har fylt ut ICMJE-skjemaet og oppgir ingen interessekonflikter.

\section{JON HENRIK LAAKE}

Jon Henrik Laake er dr.med. og overlege ved intensivavdelingen på Rikshospitalet, ansatt ved Akuttklinikken ved Oslo universitetssykehus. Han er nestleder i Norsk anestesiologisk forening og leder av Acute respiratory failure task force i Scandinavian Society of Anaesthesiology and Intensive Care Medicine.

Forfatteren har fylt ut ICMJE-skjemaet og oppgir ingen interessekonflikter.

\section{KRISTIN HOFS $\varnothing$}

Kristin Hofsø er intensivsykepleier, postdok ved Akuttklinikken ved Oslo universitetssykehus og førsteamanuensis ved Lovisenberg diakonale høgskole. Hun leder en nasjonal oppfølgingsstudie av covid-19-overlevere etter intensivopphold.

Forfatteren har fylt ut ICMJE-skjemaet og oppgir ingen interessekonflikter.

\section{Samfunnet gjør nå en stor innsats for at så mange som mulig skal overleve alvorlig covid-19-sykdom. Jobben bør ikke slutte der - vi må også sørge for at de reddede livene blir så gode som mulig.}




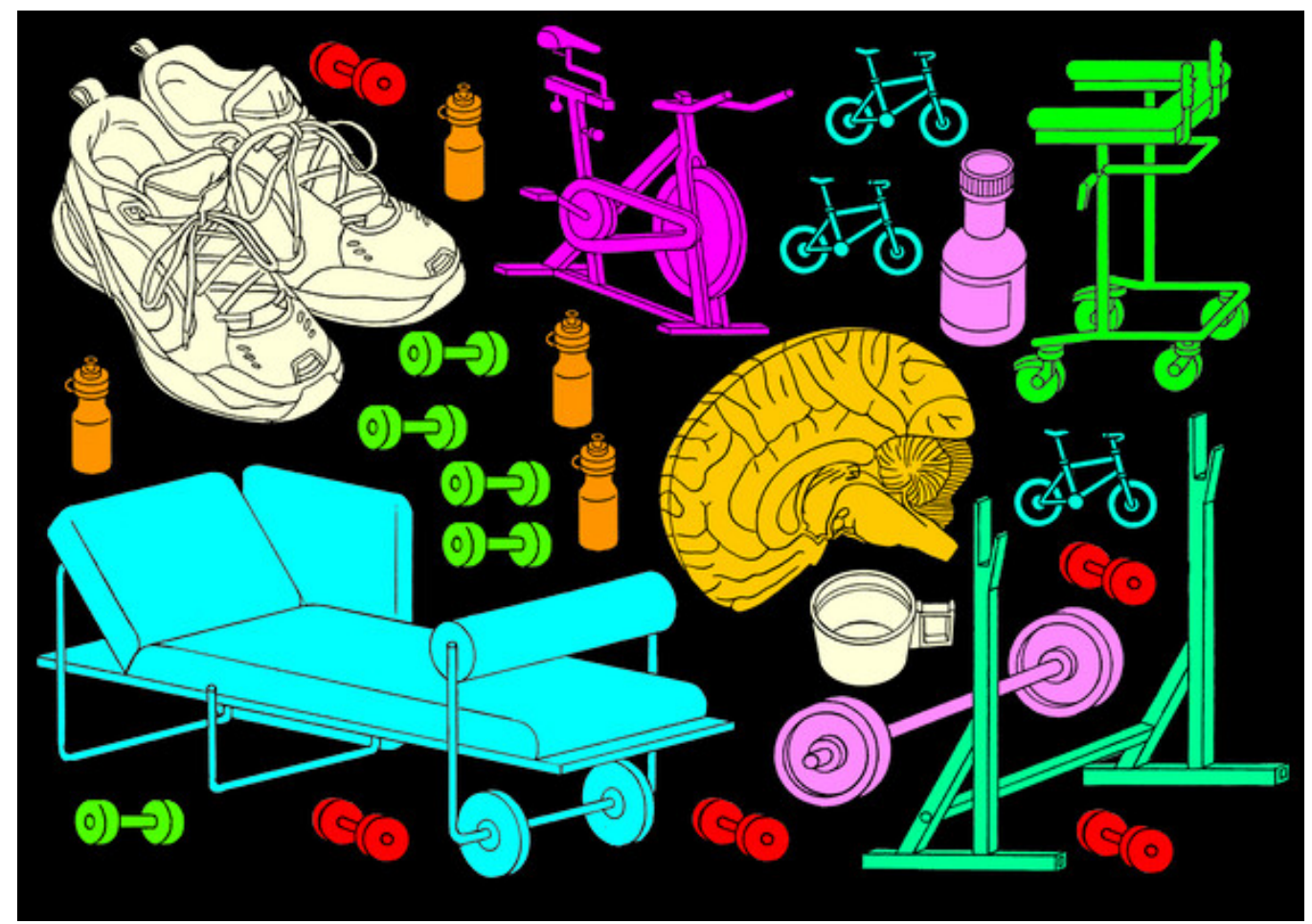

Illustrasjon: Tim Ng Tvedt

Mange av dem som overlever alvorlig covid-19, vil ha (lang)varige funksjonsnedsettelser. Kritisk sykdom med lengre intensivbehandling medfører behov for omfattende, langvarig og koordinert helsehjelp (1 1 ). Vi må sørge for gode tilbud med oppfølging og rehabilitering av covid-19-overlevere. Det er viktig at helsepersonell som møter disse pasientene etter utskrivelse, blir kjent med langtidseffektene av intensivbehandling. Som ved akuttbehandlingen av covid-19 må det også samles erfaringer og kunnskap om hva som hjelper best etter den akutte fasen, og det må lages planer for hvordan behovene for oppfølging og rehabilitering skal møtes.

\section{Stort behov for helsetjenester etter akuttfasen}

Kurativ medisin er alene ikke tilstrekkelig for å redusere følger av sykdom og for å sikre at så mange som mulig kan leve aktive og deltakende liv. Verdens helseorganisasjon (WHO) har lansert et "call for action» som understreker betydningen av å styrke rehabiliteringstjenester som en sentral helsestrategi for det 21. århundre (2ㅁ). En vesentlig erkjennelse er at helse ikke kun må ses i forhold til diagnose, men at funksjonsnivået er avgjørende for hvordan en pasient opplever sin helsetilstand (3). Spesielt avgjørende for prognosen i et slikt perspektiv er kognitiv og mental funksjon.

Langtidsfølger av intensivbehandling generelt, også kalt post-intensive care syndrome (PICS), og av akutt lungesviktsyndrom (acute respiratory distress syndrome, ARDS) spesielt, har fått $\emptyset$ kende oppmerksomhet det siste tiåret (4). Vi har lært at kritisk sykdom medfører kroniske helseplager, resulterer i multimorbiditet og kan gi en rekke (lang)varige funksjonsnedsettelser innenfor alle biopsykososiale domener (1,.5). Kritisk sykdom er en traumatisk livshendelse for hele familien. Mange pasienter har behov for langvarig, spesialisert og teambasert helsehjelp. Også familiemedlemmer kan trenge oppfølging, og dette behovet kan være enda større nå enn til vanlig fordi pårørende ikke kunne være til stede mens pasienten var innlagt. Nærhet til pasienten og regelmessig og god informasjon er av stor betydning for pårørende til intensivpasienter ( $\underline{6}$ ).

Langtidsfølgene av akutt lungesviktsyndrom inkluderer nedsatt kognitiv funksjon, psykososiale problemer (angst, depresjon), nevromuskulær svakhet, nedsatt lungefunksjon og vedvarende bruk av helsetjenester (4). Til sammen medfører dette 
nedsatt livskvalitet.

I en oppfølgingsstudie ett år etter gjennomgått influensa ( $\left.\mathrm{H}_{1} \mathrm{~N}_{1}\right)$ med alvorlig akutt lungesviktsyndrom hadde omtrent halvparten av pasientene symptomer på angst, og over en fjerdedel symptomer på depresjon (7.). Helserelatert livskvalitet var redusert sammenlignet med en matchet kontrollgruppe. Ved kognitiv kartlegging utover kun enkel screening finner man kognitive svekkelser hos $61 \%$ av pasientene med kritisk sykdom ved utreise, og hos 43 \% tolv måneder senere (모). I en nederlandsk kohort på 1700 overlevere av kritisk sykdom rapporterte $34 \%$ symptomer på angst, $33 \%$ på depresjon og $19 \%$ på posttraumatisk stress ett år etter utskrivelse (9.). En fersk metaanalyse fant at $40 \%$ av tidligere arbeidsaktive pasienter ikke var tilbake i jobb etter 12 måneder, ved oppfølging etter 42 til 60 måneder var andelen $32 \%$. For mange av dem som kom tilbake i arbeid, ble det rapportert redusert arbeidstid eller endringer i arbeidsoppgaver (10). Hele $31 \%$ av familiemedlemmene til ARDS-overlevere rapporterte symptomer på posttraumatisk stresslidelse (PTSD) seks måneder etter utskrivelse (11).

«Intensivfasen er bare starten på sykdommen for mange alvorlig rammede pasienter»

Akutt lungesviktsyndrom og langvarig respiratorbehandling forekommer hyppig ved alvorlig covid-19, og vi kan derfor forvente følgetilstander som beskrevet over. Det er i tillegg rapportert om såkalt nevro-covid-19-i en kinesisk studie hadde $45 \%$ av pasientene med alvorlig forløp nevrologiske symptomer, herunder hjerneslag og nevropatisk smerte (12). Alvorlighetsgrad og varighet av nevrologiske konsekvenser er foreløpig uklart, men kan innebære $ø$ kt behov for rehabilitering.

\section{Behovene også etter akuttfasen må ivaretas}

Både nasjonalt og internasjonalt er det nå et økende fokus på at intensivfasen bare er starten på sykdommen for mange alvorlig rammede pasienter (13-15). Selv om hovedparten av pasientene er eldre, rammes mange i aktiv alder og med mange gode år foran seg. I det første norske materialet om covid-19-pasienter med behov for innleggelse var over $40 \%$ av pasientene under 70 år (1흐). Det er betydelig usikkerhet rundt den videre utviklingen av covid-19-pandemien, men vi kan forvente et stort antall pasienter med behov for oppfølging og rehabilitering. Rapporter etter flere virusutbrudd de siste tiårene antyder at rehabilitering og tverrfaglig oppfølging forbedrer utfallet (17.). WHO har derfor understreket at rehabilitering bør være en integrert del av helsevesenets tiltak ved katastrofer (묘).

Vi må anta at eksisterende kunnskap om hva som er nyttig ved rehabilitering etter kritisk sykdom, kan ekstrapoleres til pasienter med covid-19. Tidlig intervensjon for å oppnå størst mulig effekt, tverrfaglig tilnærming med god koordinering og samarbeid mellom aktørene og en strukturert rehabiliteringsprosess er sentrale elementer. En vellykket prosess innebærer funksjonskartlegging, definisjon av rehabiliteringsmål, valg av tiltak og regelmessig evaluering, med involvering av pasient og pårørende (19). For noen pasienter handler det først og fremst om å måtte akseptere varig funksjonsnedsettelse og å få hjelp til å mestre en ny hverdag $(\underline{20})$.

«Det som er viktig nå, er at pasientenes rehabiliteringsbehov faktisk kartlegges» 
Tidlig rehabilitering bør være en integrert del av akuttbehandlingen for alle pasienter og omtales ikke nærmere her. Utskriving av covid-19-pasienter fra akuttsykehus må skje på en sikker måte der oppfølgingsbehov utover det respiratoriske bør være vurdert. Dette inkluderer en vurdering av om pasienten klarer seg hjemme, fallrisiko, kognitiv funksjon, svelgefunksjon og ernæringsstatus. Ved utreise bør individuelt vurderte rehabiliteringsbehov være dokumentert og formidlet til helsepersonell som skal følge opp pasienten.

Mange vil ha behov for rehabiliteringstiltak utover akuttinnleggelse i sykehus, særlig fordi liggetider i sykehus etter intensivopphold er korte, spesielt under en pandemi. Pasienter med behov for rehabilitering og med nedsatt ADL-funksjon bør overføres direkte til rehabiliteringsavdeling eller-institusjon.

Blant aktuelle rehabiliteringstiltak er mobilisering, kondisjons-, styrke- og balansetrening, trening av aktiviteter i dagliglivet, ivaretakelse av ernæringsbehov og svelgefunksjon og behandling av smerte samt psykologisk støtte og nevropsykologisk rehabilitering (13). Familiemedlemmer bør tilbys psykososial støtte. Figur 1 viser ulike rehabiliteringstiltak som kan være aktuelle. Når man har vært gjennom alvorlig sykdom, er det vanlig at følgetilstander og dertil relaterte behov først viser seg en stund etter akuttfasen. Initialt dominerer gleden over å ha overlevd livstruende sykdom, mens mer subtile, men likevel betydelig begrensende endringer først blir erkjent når man kommer tilbake til hverdagen. Dette gjelder spesielt emosjonelle og kognitive følger. Det er derfor avgjørende med kartlegging av både fysiske, kognitive, emosjonelle og sosiale rehabiliteringsbehov (14.). En måte å gjøre dette på er å etablere lenge etterspurte intensivmedisinske poliklinikker der sykehuset innkaller alle pasienter som har ligget på intensivavdeling i mer enn tre dager, til konsultasjon og oppfølging f.eks. etter tre måneder. Disse møtene mellom intensivpersonell og pasient, i samarbeid med rehabiliteringsmedisinsk kompetanse, har terapeutisk betydning. Samtidig kan behovet for rehabilitering og videre henvisninger til spesialister avdekkes. Såkalte intensivpoliklinikker er utbredt i flere andre land og har vakt $\emptyset$ kende interesse (1). Å få etablert slike intensivmedisinske poliklinikker bør gis høy prioritet, men tidlig i pandemien vil det være krevende. For overlevere av alvorlig covid-19 kan derfor andre modeller være aktuelle, men det som er viktig nå, er at pasientenes rehabiliteringsbehov faktisk kartlegges. 


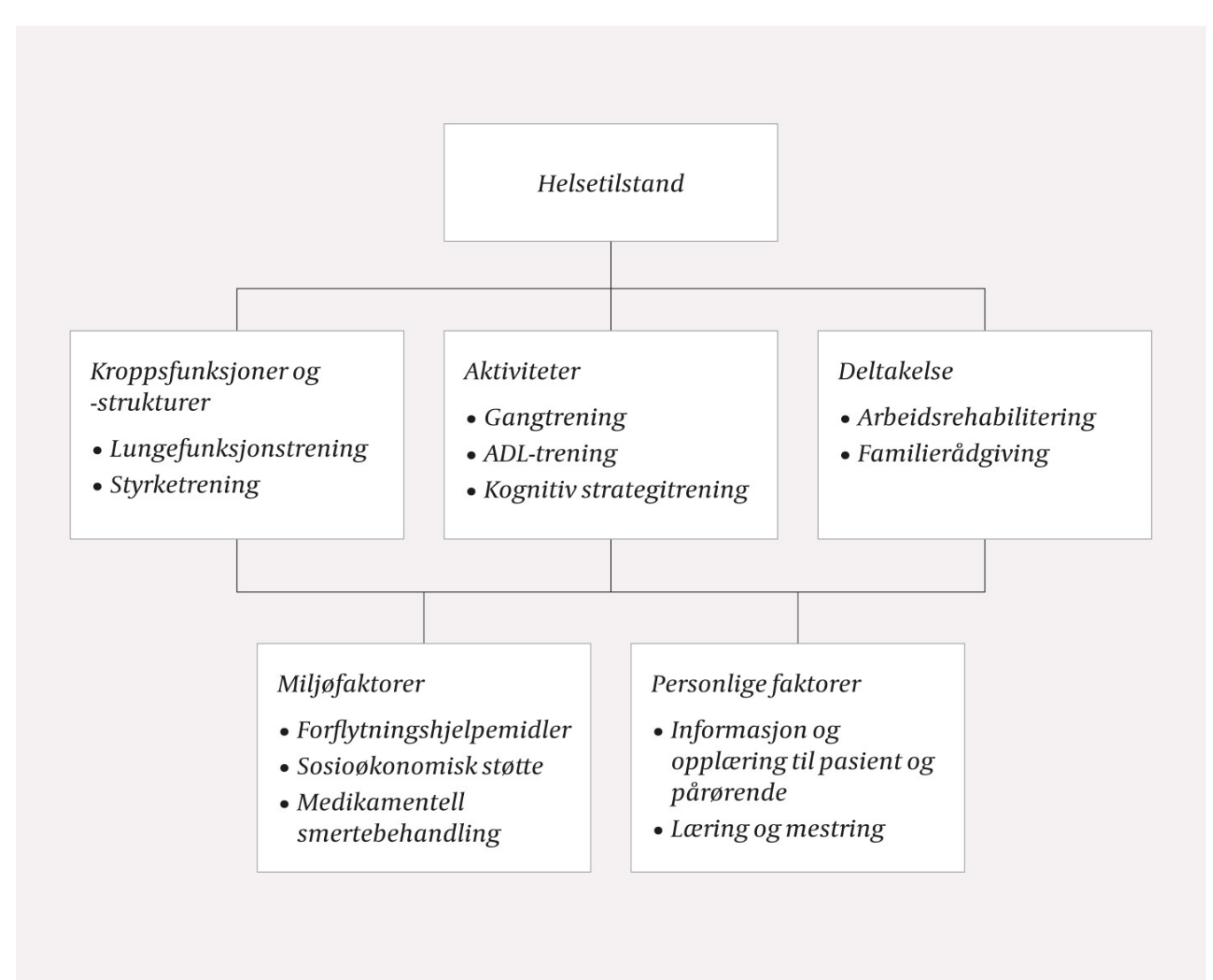

Figur 1 Eksempler på aktuelle rehabiliteringstiltak etter alvorlig covid-19, relatert til domener i Internasjonal klassifikasjon av funksjon, funksjonshemming og helse (ICF).

\section{Et reddet liv skal også leves}

Status i rehabiliteringsfeltet før pandemien startet, viser at man er langt fra rustet til å gi et godt tilbud til et stort antall covid-19-overlevere. Antall rehabiliteringspasienter i spesialisthelsetjenesten og antall registrerte rehabiliteringsaktiviteter i kommunene har

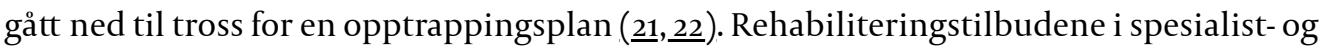
kommunehelsetjenesten varierer betydelig og beskrives som mangelfulle. Mange kommuner mangler nøkkelpersonell, har ikke oversikt over befolkningens behov for rehabilitering og har til dels stor kapasitetsmangel (23).

Det blir utfordrende for helsetjenesten å møte rehabiliteringsbehovene i forbindelse med covid-19, og det er behov for å legge planer også for denne «bølgetoppen». Vi vet at mange pasienter vil ha behov, men omfanget er usikkert. Vi trenger derfor mer kunnskap om hvordan det går med covid-19-pasientene etter akuttfasen. Rehabiliteringsenheter i spesialist- og kommunehelsetjenesten bør samle data og rapportere erfaringer.

Internasjonal konsensus om relevante effektmål bør brukes som utgangspunkt (244.).

I sum må helsemyndighetene og ansvarlige for helsetjenester på alle nivåer forberede seg på de økte oppfølgings- og rehabiliteringsbehovene som oppstår som følge av pandemien. Slik det fortløpende gjøres for akuttbehandlingen, kan vi benytte tiden som nå er vunnet, til å sørge for gode oppfølgings- og rehabiliteringstilbud (se ramme 1) (25). Når samfunnet nå gjør en stor innsats med betydelige konsekvenser for hele befolkningen, bør vi ikke stoppe halvveis. De som overlever alvorlig covid-19, må få forsvarlig og kunnskapsbasert helsehjelp gjennom hele forløpet. Som ledende europeiske rehabiliteringsmedisinere har formulert det: «Å tenke at pasienter som overlever flere uker med intensivbehandling og mekanisk ventilasjon, bare kan utskrives hjem uten videre oppfølging, er en farlig illusjon» (14, vår oversettelse). 


\section{Ramme 1 Informasjon om rehabiliteringstilbud}

De regionale koordinerende enhetene (RKE) gir informasjon om tilbudene innen habilitering og rehabilitering i sine respektive helseregioner på sine nettsider og på ReHabiliteringstelefonen 80030061.

Sunnaas sykehus har nå etablert en utvidet veiledningstjeneste for rehabilitering der alle kan få informasjon, råd og veiledning om rehabilitering (25).

\section{LITTERATUR}

1. Herridge MS. Fifty years of research in ARDS. Long-term follow-up after acute respiratory distress syndrome. Insights for managing medical complexity after critical illness. Am J Respir Crit Care Med 2017; 196: 1380-4. [PubMed][CrossRef]

2. Stucki G, Bickenbach J, Gutenbrunner C et al. Rehabilitation: The health strategy of the 21st century. J Rehabil Med 2018; 50:309-16. [PubMed][CrossRef]

3. Direktoratet for e-helse. ICF, Internasjonal klassifikasjon av funksjon, funksjonshemming og helse. https://ehelse.no/kodeverk/icf-internasjonal-klassifikasjon-av-funksjon-funksjonshemming-og-helse Lest 20.4.2020.

4. Mart MF, Ware LB. The long-lasting effects of the acute respiratory distress syndrome. Expert Rev Respir Med 2020; 14: 577-86. [PubMed][CrossRef]

5. Rawal G, Yadav S, Kumar R. Post-intensive care syndrome: an overview. J Transl Int Med 2017; 5: 90-2. [PubMed][CrossRef]

6. Strømskag KE, Opstad R. Pårørende til pasienter med covid-19 trenger oss. Tidsskr Nor Legeforen 2020; 140. doi: 10.4045/tidsskr.20.0294. [PubMed][CrossRef]

7. Luyt CE, Combes A, Becquemin MH et al. Long-term outcomes of pandemic 2009 influenza $\mathrm{A}\left(\mathrm{H}_{1} \mathrm{~N}_{1}\right)$-associated severe ARDS. Chest 2012; 142: 583-92. [PubMed][CrossRef]

8. Honarmand K, Lalli RS, Priestap F et al. Natural history of cognitive impairment in critical illness survivors: A systematic review. Am J Respir Crit Care Med 2020; 201. doi: 10.1164/rccm.201904-o816CI. [PubMed][CrossRef]

9. Dijkstra-Kersten SMA, Kok L, Kerckhoffs MC et al. Neuropsychiatric outcome in subgroups of Intensive Care Unit survivors: Implications for after-care. J Crit Care 2020; 55: 171-6. [PubMed] [CrossRef]

10. Kamdar BB, Suri R, Suchyta MR et al. Return to work after critical illness: a systematic review and meta-analysis. Thorax 2020; 75: 17-27. [PubMed][CrossRef]

11. Lee RY, Engelberg RA, Curtis JR et al. Novel risk factors for posttraumatic stress disorder symptoms in family members of acute respiratory distress syndrome survivors. Crit Care Med 2019; 47: 934-41. [PubMed][CrossRef]

12. Mao L, Jin H, Wang M et al. Neurologic manifestations of hospitalized patients with coronavirus disease 2019 in Wuhan, China. JAMA Neurol 2020; 77. doi:10.1001/jamaneurol.2020.1127. [PubMed] [CrossRef]

13. Brugliera L, Spina A, Castellazzi P et al. Rehabilitation of COVID-19 patients. J Rehabil Med 2020; 52. doi: 10.2340/16501977-2678. [PubMed][CrossRef]

14. Stam HJ, Stucki G, Bickenbach J. Covid-19 and post intensive care syndrome: A call for action. J Rehabil Med 2020; 52. doi: 10.2340/16501977-2677. [PubMed][CrossRef]

15. British Society Of Rehabilitation Medicine (BSRM). Rehabilitation in the wake of Covid-19-A phoenix from the ashes. Issue 1, 2020. https://www.bsrm.org.uk/downloads/covid-19bsrmissue1published-27-4-2020.pdf Lest 5.5.2020.

16. Ihle-Hansen H, Berge T, Tveita A et al. Covid-19: Symptomer, forløp og bruk av kliniske skåringsverktøy hos de 42 første pasientene innlagt på et norsk lokalsykehus. Tidsskr Nor Legeforen 2020; 140. doi: 10.4045/tidsskr.20.0301. [PubMed][CrossRef]

17. Landry MD, Tupetz A, Jalovcic D et al. The novel coronavirus (COVID-19): Making a connection between infectious disease outbreaks and rehabilitation. Physiother Can 2020; 72. doi: 10.3138/ptc- 
2020-0019. [CrossRef]

18. Amatya B, Galea M, Li J et al. Medical rehabilitation in disaster relief: Towards a new perspective. J Rehabil Med 2017; 49: 620-8. [PubMed][CrossRef]

19. Månum G, Becker F. Habilitering og rehabilitering av voksne og barn med nevrologisk sykdom og skade - Rehabilitering av voksne. I: Helseth E, Rootwelt T, Harbo HF, red. Nevrologi og nevrokirurgi fra barn til voksen. Bergen: Fagbokforlaget, 2019: 555-68.

20. Turnbull AE, Hurley MS, Oppenheim IM et al. Curb your enthusiasm: Definitions, adaptation, and expectations for quality of life in ICU survivorship. Ann Am Thorac Soc 2020; 17: 406-11. [PubMed] [CrossRef]

21. Rehabilitering i spesialisthelsetjenesten, Rapport 8/2018. Oslo: Helsedirektoratet, 2018. https://www.helsedirektoratet.no/rapporter/rehabilitering-i-spesialisthelsetjenesten/2018o8\%20Analysenotat\%2orehab\%202017.pdf/_/attachment/inline/fgo46ecc-boee-4340-a275b9867810bb49:2f669dc77414ofco29f3494dbbe191bedod98864/2018o8\%20Analysenotat\%2orehab\%202017.pdf Lest 5.5.2020.

22. Nilsen L. Færre får rehabilitering i spesialisthelsetjenesten. Dagens Medisin 6.9.2018. https://www.dagensmedisin.no/artikler/2018/o9/o6/farre-far-rehabilitering-i-spesialisthelsetjenesten/ Lest 20.4.2020.

23. Statusrapport hjernehelse. IS-2588. Oslo: Helsedirektoratet, 2017.

https://helsedirektoratet.no/publikasjoner/statusrapport-hjernehelse Lest 20.4.2020.

24. Needham DM, Sepulveda KA, Dinglas VD et al. Core outcome measures for clinical research in acute respiratory failure survivors. An international modified Delphi consensus study. Am J Respir Crit Care Med 2017; 196:1122-30. [PubMed][CrossRef]

25. Sunnaas sykehus. Sunnaas sykehus tilbyr nå en utvidet veiledningstjeneste for rehabilitering. https://www.sunnaas.no/om-oss/nyheter/sunnaas-sykehus-tilbyr-na-en-utvidet-veiledningstjenestefor-rehabilitering Lest 5.5.2020.

Publisert: 20. mai 2020. Tidsskr Nor Legeforen. DOI: 10.4045/tidsskr.20.0352

Mottatt 20.4.2020, første revisjon innsendt 3.5.2020, godkjent 5.5.2020.

(C) Tidsskrift for Den norske legeforening 2023. Lastet ned fra tidsskriftet.no 26. april 2023. 